\section{Cognition, Brain Function and Plasticity in the Overweight and Obese - A Review}

\author{
Arnab Ghosal ${ }^{1}$, Abhro Kumar Ghosal' ${ }^{2 *}$ and Shomik Ghosal ${ }^{3}$ \\ ${ }^{1}$ B.Sc. (Biology), Staffordshire University, Staffordshire, UK \\ ${ }^{2}$ M.Sc. (Biomedical Science), Keele University, Staffordshire, UK
}

${ }^{3}$ Consultant Paediatrician, University Hospital of North Midlands, Staffordshire, UK

\begin{abstract}
Obesity has been a growing health concern globally. As the prevalence of obesity is increasing rapidly worldwide, studying the mechanisms, manifestations and prevention of obesity is very important. This review aims to look at brain function and cognition in those who are obese or overweight. Obesity has been a risk factor for dementia, cognitive decline and also Alzheimer's disease. There is evidence that neurological consequences can occur with obesity. The normal human energy system for obesity can become impaired, which can result in cognitive impairment. Studies have demonstrated that cognitive impairment could happen due to factors associated with obesity like diabetes, hypertension, high cholesterol and metabolic syndrome. Obesity is related with reduced brain plasticity, motor control and cognition however, the research looking at how cognitive function is influenced by obesity is limited. However, overweight and obesity, as well as their related non-communicable diseases, are largely preventable. Evidence has shown that obesity effects on cognitive function are not immediately understood as obesity may affect cognitive function of various people in different ways, especially with different age groups. More research should be carried out for understanding how structure and function of the brain may facilitate associations of age and obesity with cognition.
\end{abstract}

Keywords: Obesity; Cognition; Brain function; Brain plasticity; Alzheimer's disease

${ }^{\star}$ Corresponding author: Abhro Kumar Ghosal, M.Sc. (Biomedical Science), Keele University, Staffordshire, UK, E-mail: abhroghosal@gmail.com

Citation: Ghosal A, Ghosal AK, Ghosal S (2021) Cognition, Brain Function and Plasticity in the Overweight and Obese - A Review. J Diabetes Metab Disord 8: 040 .

Received: October 06, 2021; Accepted: October 19, 2021; Published: October 26, 2021

Copyright: (c) 2021 Ghosal A, et al. This is an open-access article distributed under the terms of the Creative Commons Attribution License, which permits unrestricted use, distribution, and reproduction in any medium, provided the original author and source are credited.

\section{Introduction}

Obesity has been a commonly known public health problem resulting in reduced life expectancy and increased mortality [1]. As stated by the World Health Organisation (WHO), obesity cases have almost tripled globally after 1975 [2]. The WHO has defined overweight and obesity as excessive or abnormal accumulation of fat which has an adverse effect on health. People who have Body Mass Index's (BMIs) between $25 \mathrm{~kg} / \mathrm{m}^{2}$ and $29.9 \mathrm{~kg} / \mathrm{m}^{2}$ are considered overweight where as those who have BMIs of $\geq 30 \mathrm{~kg} / \mathrm{m}^{2}$ are considered to be obese [3]. Childhood obesity is also common. In 2016, over 340 million adolescents and children between 5 and 19 years of age were obese or overweight [2]. Studies have found that obesity has neurological consequences. Obesity has been shown to cause decreased motor control and cognition along with changed brain plasticity [4]. As obesity has been a public health concern resulting in Type 2 Diabetes (T2D), Cardiovascular Diseases (CVDs), hypertension and dyslipidaemia, limited research is available that examines the reason for it influencing cognitive function. In this review, brain function and cognition of obese and overweight people and changes related to obesity in brain plasticity are the main focal points. The review will also cover deficit effects in relation with obesity in cognition and motor control. Finally, the implications and future research directions will be discussed.

\section{Obesity and Cognition}

In obesity, the normal human energy system physiology can become impaired and result in cognitive impairment. Obesity can affect cognition and the Central Nervous System (CNS), which includes decision making, attention, verbal learning and executive function [4]. Cognitive function is the ability of a person for gaining knowledge and information by constantly applying language skills, memory and attention [5]. Obesity can affect cognitive function due to changes in structure and brain function [6-8]. Obese females had a poor performance for executive functioning tests compared to normal weight females [8]. A reduction in executive functioning was involved with the grey matter volume reducing in the left orbito frontal region [8]. Midlife obesity can cause more dementia development for older people [9]. A systematic review compared the CVD risk factor impacts, such as obesity, T2D, dyslipidaemia and hypertension, on cognition and reported a reduction in all cognitive domains [10]. Studies have shown a negative link between brains functioning and increased body fat for old women [8].

Childhood obesity is also becoming more prevalent. Childhood obesity was found to involve deficits in cognition regarding attention and shifting abilities [11]. A cross-sectional study of overweight children established that fatness was associated with worse scores, especially of mathematics, reading and executive function, while fitness with better cognition, achievement and behaviour [12]. Overweight children have spatial cognitive task problems and results have shown differences for both mental rotation accuracy and motor ability [13]. Children who were overweight had more errors when rotation tasks were difficult in comparison with children of normal weight [13]. For adolescents and children, obesity can cause poorer cognitive performances, especially for executive functions $[14,15]$. Studies 
have found that cognitive functions, including executive and attention functions were reduced in obese adolescents [16,17]. A pilot study demonstrated that obese adolescents contained insufficient cognitive domains, including impairment in executive functions and attention [16]. The cross-sectional association between cognitive performance and Visceral Fat (VF) showed larger volumes of VF in adolescents (12-18 year olds) was involved with lower performance for the six executive function measures ( $p=0.0001$ to 0.02 ) [17].

A population based study showed associations specific to gender between impairment and obesity for the developmental functioning's specific aspects [18]. High subcutaneous and paediatric overweight fat both resulted in delayed motor development for infants [19]. Overweight children were shown to have significantly lower perceived and actual physical competence [20]. Children who were overweight contained various difficulties with fundamental movement skills [21] Lower perceived and actual physical competence may be significant contributing factors for obesity in children [20]. In obese or overweight children, fine and gross motor control were found to be poorer along with a delay in motor development [18,22-24]. Obese children displayed lower gross motor skill levels in comparison with healthy weight peers [22]. The largest differences were seen in balance and loco motor skills [22]. Overweight children had reduced performance for manual dexterity, intelligence and gross motor skills (coordination and fitness) in comparison with healthy weight children [23] and weight related differences were found in gross along with fine motor skill in children who were obese [24].

A Chinese study in patients of both genders confirmed that overweight causes decreased cognitive impairment risk in older Chinese people between 60 and 98 years of age [25]. When adjusted for hypercholesterolemia, drinking, hypertension, smoking, education level, diabetes, gender and age, overweight was largely involved with lower cognitive impairment risks [Odds Ratio (OR) $=0.458$; 95\% CI 0.298 , $0.703 ; p<0.001]$ [25]. This study confirmed that although obesity can be a factor involved with cognitive impairment, it affects cognitive function differently for various age groups [25]. In contrast, obesity had not affected cognitive task accuracies on related to planning executive function, attention or memory in premenopausal women who were healthy [26]. Morbid obesity however had been involved with larger latencies for correct responses for lower lengths of memory span and tasks specific to memory [26]. However, obesity was not related to cognitive performance in association with planning and attention executive function for women who are otherwise healthy and premenopausal [26].

\section{Cognition and Body Mass Index}

A previous systematic review showed that high BMI can be associated with poor cognitive performances, especially for processing memory and speed along with executive function domains [10]. BMI was found to be inversely associated with strength, balance, agility, running speed and fine motor precision [27]. A lower prevalence of fundamental motor skills, including running, hopping, kicking or sliding has also been observed [28]. Higher waist-to-hip ratios or BMIs for middle-aged adults had been involved with faster declines of cognition for memory and learning abilities [29,30], along with executive functioning [30]. A significant negative correlation had been located between metabolic activity and BMI for the cingulated gyrus and prefrontal cortex [7]. With increase in BMI, white matter volumes for both posterior and anterior regions appeared to be significantly larger [8].
A study in older females reported that higher BMI caused reduced grey matter volumes for the right precentral gyri, right inferior frontal and left orbito frontal including the para-hippocampal, right cerebellar regions, lingual and fusiform gyri, and increased white matter volumes in the parietal, temporal and frontal lobes [8]. A cross-sectional study which was based from population [Neurological Disorders of Central Spain (NEDICES)], looked at cognitive function for a large sample that was population-based for obese and overweight old participants in comparison with controls having a BMI of $<25 \mathrm{~kg} / \mathrm{m}^{2}$ [31]. During this study, obese and overweight participants performed poorer in formal neuropsychological tests compared with controls, suggesting that high BMI impairs cognition in older people [31]. In contrast, some studies have found that higher fat-free mass and higher adiposity for old people resulted in improved cognitive performances [32]. Higher fat-free mass and a lower BMI was found to cause slow decline of cognitive function [32], however the findings were not explained by confounding of pre-existing conditions.

Type 2 Diabetes (T2D), Fasting Plasma Insulin (FPI) levels and BMI had been hugely associated with atrophy in temporal, sub cortical and frontal brain regions [33]. BMI had been correlated negatively with brain atrophy [33]. Obese individuals with BMI more than $30 \mathrm{~kg} / \mathrm{m}^{2}$, had atrophy for the anterior cingulated gyrus, hippocampus, thalamus and frontal lobes in comparison with normal BMI people [33]. Overweight individuals contained atrophy in the corona radiate and basal ganglia of the White Matter (WM) [33]. An increased deterioration in executive functions was involved with reductions for total brain volume related to midlife obesity in individuals from the prospective Framingham Offspring Cohort Study [34]. These were related to abnormalities in myelin and neurons [35].

Increased BMI for midlife is related to myelin or neuronal abnormalities, especially for the frontal lobe [35]. Since white matter for the frontal lobes is affected by aging compared to other lobes, these results demonstrate increased aging for people with high adiposity levels [35]. As a result, higher BMI levels could increase chances of developing diseases related to age such as $\mathrm{AD}$ [35]. BMI and age of middle and older adults contributed independently to decreased brain volume [36]. People who had higher midlife BMI had reduced cognition [36] and older people had larger reduced cognition if they were obese or overweight in middle age [37,38]. Higher midlife BMI scores occur before sharper cognitive decline and lower general cognitive abilities for both males and females while associations were not mediated by increased dementia risks [37].

A Systematic review showed evidence that midlife obesity was related to cognitive aging, while on the other hand, this association was weaker in the elderly [38]. Midlife obesity (95\% CI 3.98, 1.47, Relative Risk ratios (RR) 2.42), increased cognitive impairment risks while overweight people with more than $10 \%$ weight had increased cognitive impairment risks (95\% CI 11.2, 1.62, RR 4.27) [39]. Apart from BMI, other adiposity measures can be related with brain changes and cognitive performance. Visceral adiposity had been correlated inversely with verbal attention and memory while high visceral adiposity was related to larger ventricular and smaller hippocampus volume [40]. Visceral Adipose Tissue (VAT) had negative associations for verbal attention $(r=0.18, p=0.01)$ and memory $(r=0.21, p=0.005)$ [39]. Higher VAT had associations with larger ventricular volume $(F=6.07, p=0.02)$ along with lower hippocampal volume $(F=5.39, p=0.02)[40]$. 
Atrophy of the temporal lobe was associated with higher BMI for older females [41]. However, in comparison with BMI, there was a stronger association for central adiposity with cognitive impairment dementia and development risks in women [42]. Therefore, studies which use BMI as obesity's only indicator could not be sensitive enough for capturing cognitive dysfunctions induced by obesity. A negative correlation had been determined between hippocampal volume and waist-to-hip ratio, while a positive correlation between waist-to-hip ratios and white matter hyper-intensities [43]. Smaller hippocampal volumes had been related to larger waist-to-hip ratios for older adults of both genders [43]. Maternal obesity causes hippocampal functional changes, resulting in cognitive function shortfalls, including memory and learning for offspring [44]. Neuroimaging studies have demonstrated anterior cingulate gyrus, frontal lobe atrophy, thalamus and hippocampus in obese and older people [32]. Higher BMI caused lower brain volumes for obese and overweight older participants [32]. Increases of BMI are related to deficient white matter integrity, smaller grey matter volume for various brain regions (such as the prefrontal cortex) and lower metabolic activities in the cingulate gyrus and prefrontal cortex in the uncinated fasciculus, which is a structure that connects the frontal and temporal lobes $[6-8,45,46]$. Smaller grey matter volumes within left orbitofrontal regions can be related to poorer executive performance for women who are obese [8].

\section{Obesity and Brain Plasticity}

Brain plasticity is also termed neuroplasticity, which is the ability of the brain to carry out adaptable changes and re-establish connections. Obesity can be related with reduced brain plasticity, cognition and motor control however, research which examines how it can influence cognitive function is limited. Obesity effects on motor behaviours and cognition may be assessed by a number of factors which are involved in deteriorating motor and cognitive functions. Different mechanisms such as the metabolic syndrome, including hypertension, diabetes and dyslipidaemia, are involved in obesity pathophysiology. Dysregulation of leptin and insulin, brain structure, Blood-Brain Barrier (BBB), inflammation, oxidative stress and cerebrovascular function can be affected by obesity [47-50]. Changes of structure for the hippocampus, cerebellum and medial orbitofrontal cortex that are related to memory, motor learning and control, and reward-based learning [51-53], could be linked with deficits in motor and cognitive domains.

Cognition can be affected due to obesity mainly because of changes in brain structure and function $[6,32,45]$. However, some studies suggest that metabolism changes related with obesity impair brain functions while interacting with age [54]. In obese people, the cortical thickness for the right medial orbitofrontal and left superior frontal cortex of the brain and the volumes of ventral brainstem and diencephalon become lower [55]. Various studies have suggested that obesity possibly causes the brain's structural changes which may result in cognitive changes. Studies have shown that increased body weight was related to lower whole brain volume for middle-aged adults $[36,45]$. Negative relationships between neuronal injury and grey matter density were present for hippocampus and cerebellum [56]. However, processes showing obesity's effects on the structure of the brain remain unclear.

Diet influences gut microbiota which in return affects behaviours and the brain through immune, hormonal, metabolic and neural pathways $[57,58]$. Obesity caused by diet encourages the brain's reactive oxygen species similar to adiposity and body weight $[59,60]$. High fat diets increase inflammatory signalling and oxidative stress in the brain [61]. Inflammatory signalling and oxidative stress may increase inside the brain during obesity because of diets with high fat [61]. Consumption of western diet may damage the hippocampus and lead to dementia by degrading the BBB [62]. Saturated fatty acid intake for children can impair both relational and item memories [63]. High fat diets impaired long-term spatial memory in adolescents however they did not affect short-term memory. This suggests selective consolidation impairment in the hippocampus, caused because of pro-inflammatory cytokine expressions increasing [64].

In animal studies, triglycerides lowered Insulin-like Growth Factor (IGF) passages towards brain tissue through the cerebrospinal fluid, weakened hippocampal potentiation for the longer term and inhibited leptin transportation throughout BBBs [65-67]. Insulin resistance was observed inside the cerebral cortex tissues for mice consuming high fat diets that developed degenerated synaptic integrity and reduced spatial memory [68]. Gut microbiota transplantation for mice, obese from diets, for lean mice appear to be enough for encouraging neurobehavioral changes through disrupting cerebrovascular homeostasis and increasing neuro-inflammation [69,70]. Gut microbiota modulate various neurotrophins, including synaptophysin and Brain-Derived Neurotrophic Factor (BDNF), for affecting neural plasticity [71,72]. As a result, diet can change gut microbiota, influencing neurotrophins and neurophysiology and eventually impacting behaviours and cognition.

The satiety hormone Leptin helps in controlling appetite and energy expenditure [73]. Leptin is a cytokine which is related with axonal growth, synaptogenesis or even neurogenesis additionally with hypothalamic functions [74-76]. Leptin resistance may occur in obese people [77] causing changes in energy expenditure and an increased food intake [78]. In comparison with the ones containing low leptin levels, older people with higher leptin levelshad less decline of cognitive function throughout aging [79]. People who have small waist circumference with high leptin level scan be related with less cognitive decline throughout ten years [80]. Leptin presence could reduce amyloid production and increase beta-amyloid removal [81]. Old people who have higher leptin levels have lower risks of developing dementia [82]. GABAergic neurons are neurons that produce Gamma-Amino Butyric Acid (GABA). The effects of leptin take place when it connects with presynaptic GABAergic neurons by crossing the BBB $[78,83]$. Obese mice with impaired leptin signalling were found to have increased basal hippocampal inflammation $[84,85]$ and deficits of hippocampal-dependent memory [86].

Adiponectin helps to regulate fatty acid breakdown and glucose levels. It brings its effects on the brain similar to leptin for encouraging weight reduction [87]. The level of adiponectin can be associated negatively with adiposity and protects hippocampal cells [88]. Aging animals can contain reduced hippocampal adiponectin that are independent of the high fat diet intakes [89]. As a result, adiponectin is quite useful in preventing neurodegeneration. Neurotrophins, including BDNF and Insulin-like Growth Factor $1(I G F-1)$, encourages obesity effects for behaviours and cognition. The liver produces IGF-1 which is then bound to the insulin receptors or IGF-1 in order for cell proliferation and growth to be stimulated and brain beta-amyloid clearance to be encouraged [90]. People who are obese normally have IGF-1 resistance, which damages their capabilities of preventing beta-amyloid neurodegeneration and deposition $[91,92]$. BDNF binds with many receptors, including Low-affinity Nerve Growth Factor (LNGF) and Tyrosine 
Kinase Receptor B (TrkB) receptors, for stimulating synaptogenesis, neurogenesis and supporting neuronal survival [93-95]. Low BDNF is usually present in cardio metabolic diseases [96]. Obesity caused by diet can reduce presynaptic synaptophysin and hippocampal BDNF expressions, similar to spatial learning impairments with in mice [97]. High fat diets lower BDNF levels inside the hippocampus [98] while impaired hippocampal synaptic cognition and plasticity happen due to the effects of BDNFs on dendritic spines [86].

\section{Cognitive Impairment \& Dementia}

In obesity, the normal human energy system could become impaired and can result in cognitive impairment. Dementia and cognitive impairment are common diseases related to age among people and are a huge challenge to health resources and social care [25]. Dementia is when severe cognitive decline takes place for compromising a person's daily functions [99]. Dementia has affected 47 million people around the world and could rise towards 150 million during 2050 [100]. Epidemiological data has shown that dementia can affect $5 \%$ to $10 \%$ of people who are either 65 years of age or older in countries of higher-income [101]. The yearly age-specific dementia incidence ranges from $0.1 \%$ between 60 and 64 year old people to $8.6 \%$ for 95 year old people [101]. The prevalence usually becomes double approximately every five years, when people are 65 years old or above [25]. Associations between dementia and BMI was investigated in a meta-analysis which established that obesity and overweight during midlife increases dementia risk [102]. In older adults, higher dementia risks were related to midlife overweight or obesity, especially with metabolic abnormalities [39,49,103-106]. The 10-year declines for the global cognitive scores were faster for obese people $(-0.49 ; 95 \%$ CI $-0.55,-0.42)$ compared with people of normal weight $(-0.42 ; 95 \%$ CI $-0.50,-0.34),(p=0.03)$ [105]. Being obese and under 65 years of age contained positive associations on incident dementia with Risk Ratios (RR) of 1.41 (95\% CI 1.66, 1.20), however it was opposite for those of 65 years of age or more, with a Risk Ratio (RR) of 0.83 (95\% CI 0.94, 0.74) [107]. Prevention as a result is important and research has shown preventing dementia risk factors may result in a $35 \%$ risk ratio reduction [108].

\section{Obesity, Cognition and Alzheimer's Disease}

There are risks of developing dementia with Obesity, which includes $\mathrm{AD}$, along with cognitive decline [32]. The AD prevalence during 2000 in the United States was around 4.5 million people and it was predicted that this number could increase to 14 million during 2050 [109]. Studies have demonstrated possible mechanisms for links between increased AD prevalence and obesity [8]. Cognition disorders and AD usually causes dementia for older adults most frequently compared with other conditions [99]. Studies have shown that obesity makes neurodegenerative disease risks higher including $\mathrm{AD}$ along with dementia in later life [3]. Hippocampal damage and temporal lobe atrophy are both AD hallmarks $[110,111]$. A longitudinal study demonstrated that for individuals without dementia, entorhinal cortex atrophy was related to $\mathrm{AD}$ risks [110].

There may be a transitional stage in people from normal aging to clinically probable AD [99]. Memory impairments related to no or minimal decline of functions usually occurs with this mild cognitive impairment phase [99]. A few meta-analyses have demonstrated huge links for $\mathrm{AD}$ and obesity along with different types of dementia $[102,107]$. Other studies have also indicated that obesity can increase AD risks [102], while middle age obesity could increase dementia risks in older age [112]. In a meta-analysis, the pooled Relative Risks (RRs) in $\mathrm{AD}$ along with other dementia types for the BMIs of overweight people in midlife along with normal BMIs had been $1.35(95 \%$ CI 1.54, 1.19) and $1.26(95 \%$ CI 1.44, 1.10) [102]. The pooled AD relative risks and other dementia types for the BMIs of obese people in midlife in relation with normal BMIs were 2.04 (95\% CI 2.62, $1.59)$ and $1.64(95 \%$ CI 2.00, 1.34) [102]. However BMI which was continuous for old age had no association with dementia [102].

Another meta-analysis investigated cognitive impairment before $\mathrm{AD}$ diagnosis took place, indicating deficits which were preclinical in executive functioning, perceptual speed, episodic memory and global functioning indicated AD development [113]. Based on 47 studies, this meta-analysis demonstrated marked preclinical deficits for executive functioning and perceptual speed, episodic memory, global cognitive ability, and smaller deficits in attention, visuospatial skill and verbal ability [113]. Multiple cognitive domain deficits took place before clinical AD developments [99].

\section{Inflammation and Cognition}

Obesity may cause excess fat to be stored inside the visceral tissue which can cause changes in the inflammatory system and release of free fatty acids, which can adversely affect the nervous system $[102,107]$. Animals which had diets with high fat for inducing obesity had hippocampal and structure function modifications and also memory and executive function deficits $[114,115]$. Western blot analysis for the hippocampus demonstrated higher T231 and p-Tau S202/T205 levels for older High Fat or High Cholesterol (HFHC) rats, which showed abnormal Tau protein phosphorylation which follows the HFHC diet exposure [116]. For different animals, inflammation of the hypothalamus disrupted hypothalamic integrations for autonomic or neuroendocrine signals with nutritional status or satiety, metabolic control of energy expenditure or food intake along with causing damage to BBBs for median eminences which can suggest a weakness towards circulating Free Fatty Acids (FFAs) [117].

Satiety caused by leptins is lower in obese animals while higher hypothalamic inflammatory signalling results in reduced appetite control and activity along with leptin resistance. Mice which had metabolic syndrome caused due to diets with higher fat had endoplasmic reticulum resistance within the hippocampus, resulting in calcium homeostasis and insulin signalling both becoming impaired [117]. Endoplasmic reticulum resistance results in increased folded proteins and decreased protein synthesis, which may be a physiological link between cognitive impairments and metabolic syndrome [117].

\section{Role of Insulin resistance and Obesity on Cognition}

Obesity related pathophysiological changes are present regarding reduced body fitness especially cardiovascular health, vascular changes, inflammation and insulin resistance [118,119]. Studies have shown that the metabolic syndrome can be a risk factor for increased cognitive aging, in particular for older people and those with increased inflammation levels [119]. Several mechanisms can reveal associations between the cognitive decline and metabolic syndrome, which includes macro-vascular and micro-vascular disease, insulin resistance, inflammation and adiposity [119]. Therefore, early identification and treatment are necessary.

Due to insulin resistance, cells can fail in metabolizing glucose, triggering increases of insulin. Insulin signalling can be similar with tau phosphorylation, which leads towards AD [120,121]. Insulin 
dysregulation in obese people could have larger risks of dementia. Insulin action disruptions in the brain cause neuronal function and synaptogenesis impairments. Additionally, insulin signalling controls tau protein phosphorylation, which is an early component for AD development $[120,121]$. Insulin deficiency and insulin resistance have key roles in causing neurodegeneration and cognitive impairment, especially AD [122].

Hormones such as leptin and insulin play important roles for modulating synaptic structure and function inside the CNS [123]. Insulin helps to modulate hippocampal synaptic plasticity [123]. Insulin resistance is caused by obesity or larger consumption of fat $[124,125]$. Insulin concentrations are variable for adiposity while negative relationships between insulin sensitivity and VF amounts are present [126]. Adipokines (leptin and adiponectin), were significantly correlated to insulin sensitivity [126]. Circulating insulin levels and signalling pathways become different throughout obesity; these interact with inflammatory processes for controlling behaviours and cognition [127]. Obesity is associated with increased neuro-inflammation which results in brain region dysfunction related to mood regulation, memory and learning, including the hippocampus [127]. Insulin receptors in cortical and hippocampal brain structures are widespread and insulin signalling contributes to declarative memory formation [128]. Dysfunctional insulin signalling causes inflammation and encourages tau pathology and beta-amyloid which contributes towards neurodegeneration $[129,130]$. Insulin resistance causes neurodegeneration and impairment of cognition as IGFs and insulin control brain plasticity, metabolism and neuronal survival $[115,116,122,131]$. IGFI's peripheral levels are related to regulation of glucose [131]. As observed in diabetes, obesity and aging, a reduced sensitivity to IGF-I or insulin in the brain decreases Amyloid- $\beta(A \beta)$ clearance, which can make amyloid toxicity higher [131]. IGF-I and insulin could control insulin degrading enzyme levels in the brain, also causing accumulation of $\mathrm{A} \beta$ [131].

\section{Obesity, Cognition and Type 2 Diabetes}

Insulin disturbances can take place in people who are obese $[122,132]$. Insulin resistance also has huge roles for both cognitive impairments and obesity [133]. Youth obesity increases T2D risks, causing neurocognitive deficits later on. BDNFs are proteins that help to modulate fat oxidation, neuroplasticity, appetite regulation and glucose regulation for adults. Associations between BDNF level changes and diabetes risk factor changes after exercise training lasting 6 months for obese adolescents. Concentrations of BDNF are related to retention motor skill performances once learning takes place [134]. Deficits in memory and spatial learning along with short-term memory for male offspring from obese mothers had been related to neurogenesis derived from the brain and BDNF level reductions alongside increases of apoptosis within the hippocampal dentate gyrus [44]. IGFs and insulin regulate plasticity, energy metabolism and neuronal survival, required for memory and learning [122].

\section{Discussion}

Obesity is a multifaceted condition with effect on many organ systems including the brain. It causes associated impairment of glucose metabolism and T2D which have an adverse effect on brain function. Obesity has a negative effect on the brain at all age groups. It is found to have adverse effect on the developing brain and brain plasticity as well as cognitive function in the older age group which may lead to disorders such as dementia and AD. Such conditions pose a significant health implication to those affected and challenge the health economy. Significant negative associations were found between BMI and baseline prefrontal metabolic activities which possibly had contributed to cognitive performance impairments in overweight and obese people [7]. With aging, there are higher cognitive impairment risks along with gradual decline in cognitive function [135]. Therefore, strategies are needed to reduce disease-related cognitive impairment and slow declines related with old age.

In children, obesity has been found to have an association with attention, reading, executive function, mathematics and mental rotation [11-13]. Obesity impacts adversely on fine and gross motor development in young children as well as their cognitive ability to do complex tasks and intelligence scores. A delay in motor development and poor fine and gross motor control has been observed in overweight or obese children [19-21]. Along with its importance in weight maintenance and health risk reduction throughout an epidemic of childhood obesity, physical activity could be a significant and simple process of improving mental functioning for children which is central towards cognitive development [12]. Various studies looked at relationships between cognitive impairment and obesity however study findings can differ mostly due to study populations being varied [25].

As per this review, a few studies have suggested that a high BMI may have detrimental effects in older people, especially impaired cognition. However, some studies of cognition and high BMI for older people showed differing findings. One reason could be because of the small study numbers contained in the pooled analyses [102] that may have reduced the general inability of findings. Obesity together with its effects on the BBB and pro-inflammatory cytokines may affect cognition and brain plasticity as per experimental animal studies. Insulin disturbances can take place in people who are obese $[122,132]$. Insulin resistance has huge roles for both cognitive impairment and obesity [133]. Studies have suggested changed brain activation and structure due to obesity may influence cognition $[6,8,32,45]$. Obesity can influence musculoskeletal systems into degrading motor performance [136]. As motor performances may depend on cognitive abilities [137], obesity could contribute indirectly towards motor deficits while cognitive decline takes place. Studies have shown that obesity affects both motor behaviour and cognition through various processes however the validity of these mechanisms needs to be investigated further.

Studies have shown associations between higher dementia risk and increased BMI [138], however others have shown non-linear associations [32], no associations [139] or inverse associations [140,141]. While a few studies showed harmful effects of high BMI for cognitive function, others showed improvements for cognition. Studies examining older age adiposity also have results that are conflicting. Studies comparing adiposity with older age cognition have conflicting results such as neutral effect or even neuroprotective effect however they could be explained with the choice of adiposity measures [32]. Evidence about preventing cognitive impairment related with age in older people who have interventions to their lifestyle are important, however it is still unknown if it can prevent underlying neurodegeneration [100]. There currently is limited success regarding medical treatments for dementia and cognitive impairment despite therapeutic advances. Therefore non-medical approaches such as weight reduction and exercise need to be explored in more detail. 


\section{Implications and Future Prospects}

Obesity is gradually increasing, which causes a reduced quality of life, aversive motor behaviours and cognitive effects [2]. A recent study has reported that people who are severely overweight may not be able to find new neural pathways and reconnect their brains, which may have significant implications, especially for those who have had a stroke or brain injury [142]. However, overweight and obesity, as well as their related Non-Communicable Diseases (NCDs), are largely preventable. Overweight or obesity differs between later life and mid-life because they are both risk factors in the development of incident dementia. A meta-analysis and systematic review suggested a positive association for obesity in later dementia and mid-life but the opposite in later life [107]. Therefore, there needs to be more investigations regarding whether mid-life weight reductions reduced dementia risks. While more research is required, exercise interventions which improve brain health by using neuroprotective mechanisms are promising in order to preserve cognitive performance.

\section{Conclusion}

To conclude, obesity is a large social and health issue. Other than problems related to health, obesity additionally impairs motor performance and cognition. Evidence is present that obesity has neurological consequences and affects brain structure, BBB's, cerebrovascular function, leptin/insulin dysregulation, oxidative stress and inflammation, which are involved in deteriorating motor and cognitive functions. Obesity affects cognition and motor behaviours mainly due to changes in brain functions and musculoskeletal system. Previous studies have demonstrated that brain plasticity alteration related with obesity are problems causing permanent harm, especially for younger people. As a result, combating obesity throughout childhood would be a solution. Therefore, introducing physical activity for children and adults can prevent functional decline related to old age and reduce obesity.

\section{Funding: None.}

Competing Interest: The authors have declared that that have no competing interest.

\section{References}

1. Peeters A, Barendregt JJ, Willekens F, Mackenbach JP, Al Mamun A, et al. (2003) Obesity in adulthood and its consequences for life expectancy: A life-table analysis. Ann Intern Med 138: 24-32.

2. World Health Organization (WHO) Obesity and overweight. WHO, Geneva, Switzerland.

3. Bischof GN, Park DC (2015) Obesity and Aging: Consequences for Cognition, Brain Structure, and Brain Function. Psychosom Med 77: 697709 .

4. Wang C, Chan JSY, Ren L, Yan JH (2016) Obesity reduces cognitive and motor functions across the lifespan. Neural Plasticity 2016: 2473081.

5. Hess LM,Insel KC (2007) Chemotherapy-related change in cognitive function: A conceptual model. OncolNurs Forum 34: 981-994.

6. Bolzenius JD, Laidlaw DH, Cabeen RP, Conturo TE, McMichael AR et al. (2015) Brain structure and cognitive correlates of body mass index in healthy older adults. Behav Brain Res 278: 342-347.

7. Volkow ND, Wang GJ, Telang F, Fowler JS, Goldstein RZ, et al. (2009) Inverse association between BMI and prefrontal metabolic activity in healthy adults. Obesity (Silver Spring) 17: 60-65.
8. Walther K, Birdsill AC, Glisky EL, Ryan L (2010) Structural brain differences and cognitive functioning related to body mass index in older females. Hum Brain Mapp 31: 1052-1064.

9. Whitmer RA, Gunderson EP, Barrett-Connor E, Quesenberry CP Jr, Yaffe $\mathrm{K}$ (2005) Obesity in middle age and future risk of dementia: A 27 year longitudinal population based study. BMJ 330: 1360.

10. van den Berg E, Kloppenborg RP, Kessels RP, Kappelle LJ, Biessels GJ (2009) Type 2 diabetes mellitus, hypertension, dyslipidemia and obesity: A systematic comparison of their impact on cognition. BiochimBiophysActa 1792: 470-481.

11. Cserjési R, Molnár D, Luminet O, Lénárd L (2007) Is there any relationship between obesity and mental flexibility in children? Appetite 49: 675-678.

12. Davis CL, Tomporowski PD, McDowell JE, Austin BP, Miller PH, et al. (2011) Exercise improves executive function and achievement and alters brain activation in overweight children: A randomized, controlled trial. Health Psychol 30: 91-98.

13. Jansen P, Schmelter A, Kasten L, Heil M (2011) Impaired mental rotation performance in overweight children. Appetite 56: 766-769.

14. Kamijo K, Khan NA, Pontifex MB, Scudder MR, Drollette ES, et al. (2012) The relation of adiposity to cognitive control and scholastic achievement in preadolescent children. Obesity (Silver Spring) 20: 24062411

15. Verdejo-García A, Pérez-Expósito M, Schmidt-Río-Valle J, Fernández-Serrano MJ, Cruz F, et al. (2010) Selective Alterations Within Executive Functions in Adolescents With Excess Weight. Obesity 18: 15721578 .

16. Lokken KL, Boeka AG, Austin HM, Gunstad J, Harmon CM (2009) Evidence of executive dysfunction in extremely obese adolescents: A pilot study. Surg Obes Relat Dis 5: 547-552.

17. Schwartz DH, Leonard G, Perron M, Richer L, Syme C, Veillette S, et al. (2013) Visceral fat is associated with lower executive functioning in adolescents. Int J Obes (Lond) 37: 1336-1343.

18. Mond JM, Stich H, Hay PJ, Kraemer A, Baune BT (2007) Associations between obesity and developmental functioning in pre-school children: A population-based study. Int J Obes (Lond) 31: 1068-1073.

19. Slining M, Adair LS, Goldman BD, Borja JB, Bentley M (2010) Infant overweight is associated with delayed motor development. J Pediatr157: 20-25.

20. Southall JE, Okely AD, Steele JR (2004) Actual and perceived physical competence in overweight and nonoverweight children. Pediatric Exercise Science 16: 15-24.

21. Poulsen AA, Desha L, Ziviani J, Griffiths L, Heaslop A, et al. (2011) Fundamental movement skills and self-concept of children who are overweight. Int J Pediatr Obes 6: 464-471.

22. Roberts D, Veneri D, Decker R, Gannotti M (2012) Weight status and gross motor skill in kindergarten children. PediatrPhysTher24:353-360.

23. Krombholz H (2013) Motor and cognitive performance of overweight preschool children. Percept Mot Skills 116: 40-57.

24. Gentier I, D’Hondt E, Shultz S, Deforche B, Augustijn M, et al. (2013) Fine and gross motor skills differ between healthy-weight and obese children. Res Dev Disabil 34: 4043-4051.

25. Hou Q, Guan Y, Yu W, Liu X, Wu L, et al. (2019) Associations between obesity and cognitive impairment in the Chinese elderly: An observational study. ClinInterv Aging 14: 367-373.

26. Farooq A, Gibson AM, J Reilly J, Gaoua N (2018) The Association between Obesity and Cognitive Function in Otherwise Healthy Premenopausal Arab Women. J Obes 2018: 1741962.

27. Kemp C, Pienaar AE (2013) Relationship between the body composition and motor and physical competence of Grade 1 learners in South Africa. J Sports Med Phys Fitness 53: 635-643. 
28. Cliff DP, Okely AD, Morgan PJ, Jones RA, Steele JR, et al. (2012) Proficiency deficiency: Mastery of fundamental movement skills and skill components in overweight and obese children. Obesity (Silver Spring) 20: $1024-1033$.

29. Cournot M, Marquié JC, Ansiau D, Martinaud C, Fonds H, et al. (2006) Relation between body mass index and cognitive function in healthy middle-aged men and women. Neurology 67: 1208-1214.

30. Wolf PA, Beiser A, Elias MF, Au R, Vasan RS, et al. (2007) Relation of obesity to cognitive function: Importance of central obesity and synergistic influence of concomitant hypertension. The Framingham Heart Study. Curr Alzheimer Res 4: 111-116.

31. Benito-León J, Mitchell AJ, Hernández-Gallego J, Bermejo-Pareja $\mathrm{F}$ (2013) Obesity and impaired cognitive functioning in the elderly: A population-based cross-sectional study (NEDICES). European Journal of Neurology 20: 899-906, 76-77.

32. Luchsinger JA, Biggs ML, Kizer JR, Barzilay J, Kuller L, et al. (2013) Adiposity and cognitive decline in the cardiovascular health study. Neuroepidemiology 40: 274-281.

33. Raji CA, Ho AJ, Parikshak NN, Becker JT, Lopez OL, et al. (2010) Brain structure and obesity. Human Brain Mapping 31: 353-364.

34. Debette S, Seshadri S, Beiser A, Himali JJ, Palumbo C, et al. (2011) Midlife vascular risk factor exposure accelerates structural brain aging and cognitive decline. Neurology 77: 461-468.

35. Gazdzinski S, Kornak J, Weiner MW, Meyerhoff DJ, (2008) Body mass index and magnetic resonance markers of brain integrity in adults. Annals of Neurology 63: 652-657.

36. Ward M, Carlsson CM, Trivedi M, Sager MA, Johnson SC (2005) The effect of body mass index on global brain volume in middle-aged adults: A cross sectional study. BMC Neurology 5: 23 .

37. Dahl A, Hassing LB, Fransson E, Berg S, Gatz M, et al. (2010) Being overweight in midlife is associated with lower cognitive ability and steeper cognitive decline in late life. Journals of Gerontology-Series A: Biological Sciences and Medical Sciences 65: 57-62.

38. Dahl AK, Hassing LB (2013) Obesity and cognitive aging. Epidemiologic Reviews 13: 22-32.

39. Virta JJ, Heikkilä K, Perola M, Koskenvuo M, Raiha I, et al. (2013) Midlife cardiovascular risk factors and late cognitive impairment. European Journal of Epidemiology 28: 405-416.

40. Isaac V, Sim S, Zheng H, Zagorodnov V, Tai ES, et al. (2011) Adverse associations between visceral adiposity, brain structure, and cognitive performance in healthy elderly. Frontiers in Aging Neuroscience 3: 12.

41. Gustafson D (2008)A life course of adiposity and dementia. European Journal of Pharmacology 585: 163-175.

42. Kerwin DR, Gaussoin SA, Chlebowski RT, Kuller LH, Vitolins M, et al. (2011) Interaction between body mass index and central adiposity and risk of incident cognitive impairment and dementia: results from the women's health initiative memory study. Journal of the American Geriatrics Society 59: 107-112.

43. Jagust W, Harvey D, Mungas D, Haan M (2005) Central obesity and the aging brain. Archives of Neurology 62: 1545-1548.

44. Kim TW, Park HS (2018) Physical exercise improves cognitive function by enhancing hippocampal neurogenesis and inhibiting apoptosis in male offspring born to obese mother. Behavioural Brain Research 347: 360367.

45. Taki Y, Kinomura S, Sato K, Inoue K, Goto R, et al. (2008) Relationship between body mass index and gray matter volume in 1,428 healthy individuals. Obesity 16: 119-124.

46. Willette AA, Kapogiannis D (2015) Does the brain shrink as the waist expands? Ageing Research Reviews 20: 86-97.
47. Gonzales MM, Tarumi T, Eagan DE, Tanaka H, Vaghasia M, et al. (2012) Indirect effects of elevated body mass index on memory performance through altered cerebral metabolite concentrations. Psychosomatic Medicine 74: 691-698.

48. Smith E, Hay P, Campbell L, Trollor JN (2011) A review of the association between obesity and cognitive function across the lifespan: implications for novel approaches to prevention and treatment. Obesity Reviews 12: 740-755.

49. Nguyen JCD, Killcross AS, Jenkins TA (2014) Obesity and cognitive decline: role of inflammation and vascular changes. Frontiers in Neuroscience 8: 375 .

50. Arnoldussen IAC, Kiliaan AJ, Gustafson DR (2014) Obesity and dementia: adipokines interact with the brain. European Neuropsychopharmacology 24: 1982-1999.

51. Walton ME, Behrens TEJ, Buckley MJ, Rudebeck PH, Rushworth MFS (2010) Separable learning systems in the macaque brain and the role of orbitofrontal cortex in contingent learning. Neuron 65: 927-939.

52. Squire LR (1992) Memory and the hippocampus-a synthesis from findings with rats, monkeys, and humans. Psychological Review 99: 195-231.

53. Doya K (2000) Complementary roles of basal ganglia and cerebellum in learning and motor control. Current Opinion in Neurobiology 10: 732739 .

54. Keller AJB, Keller JN, Morrison CD (2009) Obesity and vulnerability of the CNS. BiochimicaetBiophysicaActa-Molecular Basis of Disease 1792: $395-400$

55. Iturria IM, Pueyo R, Garolera M, Segura B, Junqué C, et al. (2013) Frontal cortical thinning and subcortical volume reductions in early adulthood obesity. Psychiatry Research Neuroimaging 214: 109-115.

56. Mueller K, Sacher J, Arelin K, Holiga S, Kratzsch J, et al. (2012) Overweight and obesity are associated with neuronal injury in the human cerebellum and hippocampus in young adults: a combined MRI, serum marker and gene expression study. Translational Psychiatry 2: 200.

57. Luna RA, Foster JA (2015) Gut brain axis: diet microbiota interactions and implications for modulation of anxiety and depression. Current Opinion in Biotechnology 32: 35-41.

58. Moloney RD, Desbonnet L, Clarke G, Dinan TG, Cryan JF (2014) The microbiome: Stress, health and disease. Mammalian Genome 25: 49-74.

59. Morrison CD, Pistell PJ, Ingram DK, Johnson WD, Liu Y, et al. (2010) High fat diet increases hippocampal oxidative stress and cognitive impairment in aged mice: Implications for decreased Nrf2 signaling. Journal of Neurochemistry 114: 1581-1589.

60. Freeman LR, Zhang L, Nair A, Dasuri K, Francis J, et al. (2013) Obesity increases cerebrocortical reactive oxygen species and impairs brain function. Free Radical Biology and Medicine 56: 226-233.

61. White CL, Pistell PJ, Purpera MN, Gupta S, Kim SOF, et al. (2009) Effects of high fat diet on Morris maze performance, oxidative stress, and inflammation in rats: Contributions of maternal diet. Neurobiology of Disease 35: 3-13

62. Hsu TM, Kanoski SE (2014) Blood-brain barrier disruption: mechanistic links between western diet consumption and dementia. Frontiers in Aging Neuroscience 6: 88 .

63. Baym CL, Khan NA, Monti JM, Raine LB, Drollette ES, et al. (2014) Dietary lipids are differentially associated with hippocampal-dependent relational memory in prepubescent children. American Journal of Clinical Nutrition 99: 1026-1033.

64. Boitard C, Cavaroc A, Sauvant J, Aubert A, Castanon N, et al. (2014) Impairment of hippocampal-dependent memory induced by juvenile highfat diet intake is associated with enhanced hippocampal inflammation in rats. Brain, Behavior, and Immunity 40: 9-17. 
Citation: Ghosal A, Ghosal AK, Ghosal S (2021) Cognition, Brain Function and Plasticity in the Overweight and Obese - A Review. J Diabetes Metab Disord 8: 040 .

65. Dietrich MO, Muller A, Bolos M, Carro E, Perry ML, et al. (2007) Western style diet impairs entrance of blood-borne insulin-like growth factor-1 into the brain. NeuroMolecular Medicine 9: 324-330.

66. Farr SA, Yamada KA, Butterfield DA, Abdul HM, Xu L, et al. (2008) Obesity and hypertriglyceridemia produce cognitive impairment. Endocrinology 149: 2628-2636.

67. Banks WA, Coon AB, Robinson SM, Moinuddin A, Shultz JM, et al (2004) Triglycerides induce leptin resistance at the blood-brain barrier. Diabetes 53: 1253-1260.

68. Arnold SE, Lucki I, Brookshire BR, Carlson GC, Browne CA, et al. (2014) High fat diet produces brain insulin resistance, synaptodendritic abnormalities and altered behavior in mice. Neurobiol Dis 67: 79-87.

69. Bruce-Keller AJ, Salbaum JM, Luo M, Blanchard E, Taylor CM, et al. (2014) Obese-type gut microbiota induce neurobehavioral changes in the absence of obesity. Biol Psychiatry 77: 607-615

70. Moran CP, Shanahan F (2014) Gut microbiota and obesity: Role in aetiology and potential therapeutic target. Best Pract Res Clin Gastroenterol 28: $585-597$

71. Heijtz RD, Wang S, Anuar F, Qian Y, Björkholm B, et al. (2011) Norma gut microbiota modulates brain development and behavior. Proceedings of the National Academy of Sciences of the United States of America 108: 3047-3052.

72. Douglas-Escobar M, Elliott E, Neu J (2013) Effect of intestinal microbia ecology on the developing brain. JAMA Pediatr 167: 374-379.

73. Lehr S, Hartwig S, Sell H (2012) Adipokines: A treasure trove for the discovery of biomarkers for metabolic disorders. ProteomicsClinApp 16 91-101.

74. Bouret SG (2010) Neurodevelopmental actions of leptin. Brain Res 1350 2-9.

75. Oomura Y, Hori N, Shiraishi T,Fukunaga K, Takeda H, et al. (2006) Leptin facilitates learning and memory performance and enhances hippocampal CA1 long-term potentiation and CaMK II phosphorylation in rats. Peptides 27: 2738-2749.

76. Shanley LJ, Irving AJ, Harvey J (2001) Leptin enhances NMDA receptor function and modulates hippocampal synaptic plasticity. J Neurosci 21 : 186.

77. Mapfei M, Halaas J, Ravussin E, Pratley RE, Lee GH, et al. (1995) Leptin levels in human and rodent: measurement of plasma leptin and ob RNA in obese and weight-reduced subjects. Nat Med 1: 1155-1161.

78. Feng H, Zheng L, Feng Z, Zhao Y, Zhang N (2013) The role of leptin in obesity and the potential for leptin replacement therapy. Endocrine 44: 33-39.

79. Holden KF, Lindquist K, Tylavsky FA, Rosano C, Harris TB, et al. (2009) Serum leptin level and cognition in the elderly: Findings from the Health ABC Study. Neurobiology of Aging 30: 1483-1489.

80. Hazzouri ZA, Haan MN, Whitmer RA, Yaffe K, Neuhaus J (2012) Central obesity, leptin and cognitive decline: The sacramento area Latino study on aging. Dementia and Geriatric Cognitive Disorders 33: 400-409.

81. Folch J, Pedrós I, Patraca I, Sureda F, Junyent F, et al. (2012) Neuroprotective and anti-ageing role of leptin. Journal of Molecular Endocrinology 49: 149-156.

82. Lieb W, Beiser AS, Vasan RS, Au Rhoda, Harris TB, et al. (2009) Association of plasma leptin levels with incident Alzheimer disease and MRI measures of brain aging. The Journal of the American Medical Association 302: $2565-2572$.

83. Coppari R, Bjørbæk C (2012) Leptin revisited: Its mechanism of action and potential for treating diabetes. Nature Reviews Drug Discovery 11 $692-708$
84. Dinel AL, André C, Aubert A, Ferreira G, Layé S, et al. (2011) Cognitive and emotional alterations are related to hippocampal inflammation in a mouse model of metabolic syndrome. PLoS ONE 6: e24325.

85. Erion JR, Wosiski-Kuhn M, Dey A, Hao S, Davis CL, et al. (2014) Obesity elicits interleukin 1-mediated deficits in hippocampal synaptic plasticity. The Journal of Neuroscience 34: 2618-2631.

86. Stranahan AM, Arumugam TV, Cutler RG, Lee K, Egan JM, et al. (2008) Diabetes impairs hippocampal function through glucocorticoid-mediated effects on new and mature neurons. Nature Neuroscience 11: 309-317.

87. Nedvídková J, Smitka K, Kopský V, Hainer V (2005) Adiponectin, an adipocyte-derived protein. Physiol Res 54: 133-140.

88. Letra L, Santana I, Seiça R (2014) Obesity as a risk factor for Alzheimer's disease: the role of adipocytokines. Metab Brain Dis 29: 563-568.

89. Pancani T, Anderson KL, Brewer LD, Kadish I, DeMoll C, et al. (2013) Effect of high-fat diet on metabolic indices, cognition, and neuronal physiology in aging F344 rats. Neurobiol Aging 34: 1977-1987.

90. Carro E, Trejo JL, Gomez-Isla T, LeRoith D, Torres-Aleman I (2002) Serum insulin-like growth factor I regulates brain amyloid- $\beta$ levels. Nat Med 8: 1390-1397.

91. Messier C, Teutenberg K (2005) The role of insulin, insulin growth factor, and insulin-degrading enzyme in brain aging and Alzheimer's disease. Neural Plast 12: 311-328.

92. Spielman LJ, Little JP, Klegeris (2014) Inflammation and insulin/IGF-1 resistance as the possible link between obesity and neurodegeneration. $\mathrm{J}$ Neuroimmunol 273: 8-21

93. Huang EJ, Reichardt LF (2001) Neurotrophins: roles in neuronal development and function. Annu Rev Neurosci 24: 677-736.

94. Patapoutian A, Reichardt LF (2001) Trk receptors: mediators of neurotrophin action. Curr Opin Neurobiol 11: 272-280.

95. Yancopoulos GD, Lindsay RM (1995) A BDNF autocrine loop in adult sensory neurons prevents cell death. Nature 374: 450-453.

96. Chaldakov GN, Tonchev AB, Aloe L (2009) NGF and BDNF: From nerves to adipose tissue, from neurokines to metabokines. Riv Psichiatr 44: 79-87.

97. Baumgarner KM, Setti S, Diaz C, Littlefield A, Jones A, et al. (2014) Diet-induced obesity attenuates cytokine production following an immune challenge. Behav Brain Res 267: 33-41.

98. Park HR, Park M, Choi J, Park K-Y, Chung HY, et al. (2010) A highfat diet impairs neurogenesis: involvement of lipid peroxidation and brain-derived neurotrophic factor. Neurosci Lett 482: 235-239.

99. Kelley BJ, Petersen RC (2007) Alzheimer's disease and mild cognitive impairment. Neurol Clin 25: 577-609.

100. Broadhouse KM, Singh MF, Suo C, Gates N, Wen W, et al. (2020) Hippocampal plasticity underpins long-term cognitive gains from resistance exercise in MCI. Neuroimage Clin 25: 102182

101. Hugo J, Ganguli M (2014) Dementia and cognitive impairment: Epidemiology, diagnosis, and treatment. Clin Geriatr Med 30: 421-42.

102. Anstey KJ, Cherbuin N, Budge M, Young J (2011) BMI in midlife and late life as a risk for dementia: A meta-analysis of prospective studies. Obes Rev 12: 426-437.

103. Gustafson DR (2012) Adiposity and cognitive decline: underlying mechanisms. J Alzheimers Dis 30: 97-112.

104. García-Ptacek S, Faxén-Irving G, Čermáková P, Eriksdotter M, Religa D (2014) Body mass index in dementia. Eur J Clin Nutr 68: 1204-1209.

105. Singh-Manoux A, Czernichow S, Elbaz A, Dugravot A, Sabia S, et al (2012) Obesity phenotypes in midlife and cognition in early old age: The Whitehall II cohort study. Neurology 79: 755-762. 
106. Tolppanen AM, Ngandu T, Kåreholt I, Laatikainen T, Rusanen M, et al. (2014) Midlife and late-life body mass index and late-life dementia: Results from a prospective population-based cohort. J Alzheimers Dis 38: 201-209.

107. Pedditizi E, Peters R, Beckett N (2016) The risk of overweight/obesity in mid-life and late life for the development of dementia: A systemic review and meta-analysis of longitudinal studies. Age Ageing 45: 14-21.

108. Livingston G, Sommerlad A, Orgeta V, Costafreda SG, Huntley J, et al. (2017) Dementia prevention, intervention, and care. Lancet 390: 2673 2734.

109. Brookmeyer R, Gray S, Kawas C (1998) Projections of Alzheimer's disease in the United States and the public health impact of delaying disease onset. Am J Public Health 88: 1337-1342.

110. Stoub TR, Bulgakova M, Leurgans S, Bennett DA, Fleischman D, et al (2005) MRI predictors of risk of incident Alzheimer disease: A longitudinal study. Neurology 64: 1520-1524.

111. Whitwell JL, Przybelski SA, Weigand SD, Knopman DS, Boeve BF, et al. (2007) 3D maps from multiple MRI illustrate changing atrophy patterns as subjects progress from mild cognitive impairment to Alzheimer's disease. Brain 130: 1777-1786.

112. Whitmer RA, Gustafson DR, Barrett-Connor E, Haan MN, Gunderson EP, et al. (2008) Central obesity and increased risk of dementia more than three decades later. Neurology 71: 1057-1064.

113. Bäckman L, Jones S, Berger AK, Laukka EJ, Small BJ (2005) Cognitive impairment in preclinical Alzheimer's disease: a meta-analysis. Neuropsychology 19: 520-531.

114. Jurdak N, Lichtenstein AH, Kanarek RB (2008) Diet induced obesity and spatial cognition in young male rats. Nutr Neurosci 11: 48-54.

115. Ledreux A, Wang X, Schultzberg M, Granholm AC, Freeman LR (2016) Detrimental effects of a high fat, high cholesterol diet on memory and hippocampal markers in aged rats. Behav Brain Res 312: 294-304.

116. Richard D (2015) Cognitive and autonomic determinants of energy homeostasis in obesity. Nat Rev Endocrinol 11: 489-501.

117. Sims-Robinson C, Bakeman A, Glasser R, Boggs J, Pacut C, et al. (2016) The role of endoplasmic reticulum stress in hippocampal insulin resistance. Exp Neurol 277: 261-267.

118. Shefer G, Marcus Y, Stern N (2013) Is obesity a brain disease? Neuroscience \& Biobehavioral Reviews 37: 2489-2503.

119. Yaffe K (2007) Metabolic syndrome and cognitive decline, Current Alzheimer Research 4: 123-126.

120. Craft S (2005) Insulin resistance syndrome and Alzheimer's disease: age- and obesity-related effects on memory, amyloid and inflammation. Neurobiology of Aging 26: 65-69.

121. Kleinridders A, Ferris HA, Cai WK, Kahn CR (2014) Insulin action in brain regulates systemic metabolism and brain function. Diabetes 63 . $2232-2243$

122. Monte SM (2009) Insulin resistance and Alzheimer's disease. BMB Reports 42: 475-481.

123. Moult PR, Harvey J (2008) Hormonal regulation of hippocampal dendritic morphology and synaptic plasticity. Cell Adhesion \& Migration. 2: 269-275.

124. Figlewicz DP, Bennett JL, Naleid AM, Davis C, Grimm JW (2006) Intraventricular insulin and leptin decrease sucrose self-administration in rats. Physiology and Behavior 89: 611-616.
125. Qatanani M, Lazar MA (2007) Mechanisms of obesity-associated insulin resistance: Many choices on the menu. Genes and Development 21: 1443-1455

126. Maffeis C, Manfredi R, Trombetta M, Sordelli S, Storti M, et al. (2008) Insulin sensitivity is correlated with subcutaneous but not visceral body fat in overweight and obese prepubertal children. Journal of Clinical Endocrinology and Metabolism 93: 2122-2128.

127. Castanon N, Luheshi G, Layé S. Role of neuroinflammation in the emotional and cognitive alterations displayed by animal models of obesity. Frontiers in Neuroscience 9: 229

128. Unger JW, Livingston JN, Moss AM (1991) Insulin receptors in the cen tral nervous system: localization, signalling mechanisms and functional aspects. Progress in Neurobiology 36: 343-362.

129. Cholerton B, Baker LD, Craft S (2011) Insulin resistance and pathological brain ageing. Diabetic Medicine 28: 1463-1475.

130. Kim B, Feldman EL (2015) Insulin resistance as a key link for the in creased risk of cognitive impairment in the metabolic syndrome. Experimental \& Molecular Medicine 47: 149.

131. Messier C, Teutenberg K (2005) The role of insulin, insulin growth factor, and insulin-degrading enzyme in brain aging and Alzheimer's disease. Neural Plasticity 12: 311-328.

132. Freiherr J, Hallschmid M, Frey WH, Brunner YF, Chapman CD, et al (2013) Intranasal insulin as a treatment for alzheimer's disease: A review of basic research and clinical evidence. CNS Drugs 27: 505-514.

133. Ott V, Benedict C, Schultes B, Born J, Hallschmid M (2012) Intranasal administration of insulin to the brain impacts cognitive function and peripheral metabolism. Diabetes, Obesity and Metabolism 14: 214-221.

134. Skriver K, Roig M, Lundbye-Jensen J, Pingel J, Helge W, et al. (2014) A cute exercise improves motor memory: Exploring potential biomarkers. Neurobiology of Learning and Memory 116: 46-58.

135. Brayne C, Gill C, Paykel ES, Huppert F, O'Connor DW (1995) Cognitive decline in an elderly population-a two wave study of change. Psychol Med 25: 673-683.

136. Moore AZ, Caturegli G, Metter EJ, Makrogiannis S, Resnick SM, et al (2014) Difference in muscle quality over the adult life span and biological correlates in the baltimore longitudinal study of aging. Journal of the American Geriatrics Society 62: 230-236.

137. Mignardot J-B, Olivier I, Promayon E, Nougier V (2010) Obesity impact on the attentional cost for controlling posture. PLoS ONE 5: 14387.

138. Gustafson D, Rothenberg E, Blennow K, Steen B, Skoog I (2003) An 18-Year Follow-up of Overweight and Risk of Alzheimer Disease. Arch Intern Med 163: 1524-1528.

139. Fitzpatrick AL, Kuller LH, Lopez OL, Diehr P, O’Meara ES, et al. (2009) Midlife and late-life obesity and the risk of dementia: Cardiovascular health study. Arch Neurol 66: 336-342.

140. Nourhashemi F, Deschamps V, Larrieu S, Letenneur L, Dartigues JF, et al. (2003) Body mass index and incidence of dementia: The PAQUID study. Neurology 60: 117-119.

141. Stewart R, Masaki K, Xue Q-L, Peila R, Petrovitch H, (2005) A 32-Year Prospective Study of Change in Body Weight and Incident Dementia: The Honolulu-Asia Aging Study. Arch Neurol 62: 55-60.

142. Sophia XS, Ridding, MC, Hordacre B (2020) Obesity is Associated with Reduced Plasticity of the Human Motor Cortex. Brain Sciences 10: 579. 


\section{$\mathbb{d}$ \\ Hнram}

Advances In Industrial Biotechnology | ISSN: 2639-5665

Advances In Microbiology Research | ISSN: 2689-694X

Archives Of Surgery And Surgical Education | ISSN: 2689-3126

Archives Of Urology

Archives Of Zoological Studies | ISSN: 2640-7779

Current Trends Medical And Biological Engineering

International Journal Of Case Reports And Therapeutic Studies | ISSN: 2689-310X

Journal Of Addiction \& Addictive Disorders | ISSN: 2578-7276

Journal Of Agronomy \& Agricultural Science | ISSN: 2689-8292

Journal Of AIDS Clinical Research \& STDs | ISSN: 2572-7370

Journal Of Alcoholism Drug Abuse \& Substance Dependence | ISSN: 2572-9594

Journal Of Allergy Disorders \& Therapy | ISSN: 2470-749X

Journal Of Alternative Complementary \& Integrative Medicine | ISSN: 2470-7562

Journal Of Alzheimers \& Neurodegenerative Diseases | ISSN: 2572-9608

Journal Of Anesthesia \& Clinical Care | ISSN: 2378-8879

Journal Of Angiology \& Vascular Surgery | ISSN: 2572-7397

Journal Of Animal Research \& Veterinary Science | ISSN: 2639-3751

Journal Of Aquaculture \& Fisheries | ISSN: 2576-5523

Journal Of Atmospheric \& Earth Sciences | ISSN: 2689-8780

Journal Of Biotech Research \& Biochemistry

Journal Of Brain \& Neuroscience Research

Journal Of Cancer Biology \& Treatment | ISSN: 2470-7546

Journal Of Cardiology Study \& Research | ISSN: 2640-768X

Journal Of Cell Biology \& Cell Metabolism | ISSN: 2381-1943

Journal Of Clinical Dermatology \& Therapy | ISSN: 2378-8771

Journal Of Clinical Immunology \& Immunotherapy | ISSN: 2378-8844

Journal Of Clinical Studies \& Medical Case Reports | ISSN: 2378-8801

Journal Of Community Medicine \& Public Health Care | ISSN: 2381-1978

Journal Of Cytology \& Tissue Biology | ISSN: 2378-9107

Journal Of Dairy Research \& Technology | ISSN: 2688-9315

Journal Of Dentistry Oral Health \& Cosmesis | ISSN: 2473-6783

Journal Of Diabetes \& Metabolic Disorders | ISSN: 2381-201X

Journal Of Emergency Medicine Trauma \& Surgical Care | ISSN: 2378-8798

Journal Of Environmental Science Current Research | ISSN: 2643-5020

Journal Of Food Science \& Nutrition | ISSN: 2470-1076

Journal Of Forensic Legal \& Investigative Sciences | ISSN: 2473-733X

Journal Of Gastroenterology \& Hepatology Research | ISSN: 2574-2566
Journal Of Genetics \& Genomic Sciences | ISSN: 2574-2485

Journal Of Gerontology \& Geriatric Medicine | ISSN: 2381-8662

Journal Of Hematology Blood Transfusion \& Disorders | ISSN: 2572-2999

Journal Of Hospice \& Palliative Medical Care

Journal Of Human Endocrinology | ISSN: 2572-9640

Journal Of Infectious \& Non Infectious Diseases | ISSN: 2381-8654

Journal Of Internal Medicine \& Primary Healthcare | ISSN: 2574-2493

Journal Of Light \& Laser Current Trends

Journal Of Medicine Study \& Research | ISSN: 2639-5657

Journal Of Modern Chemical Sciences

Journal Of Nanotechnology Nanomedicine \& Nanobiotechnology | ISSN: 2381-2044 Journal Of Neonatology \& Clinical Pediatrics | ISSN: 2378-878X

Journal Of Nephrology \& Renal Therapy | ISSN: 2473-7313

Journal Of Non Invasive Vascular Investigation | ISSN: 2572-7400

Journal Of Nuclear Medicine Radiology \& Radiation Therapy | ISSN: 2572-7419

Journal Of Obesity \& Weight Loss | ISSN: 2473-7372

Journal Of Ophthalmology \& Clinical Research | ISSN: 2378-8887

Journal Of Orthopedic Research \& Physiotherapy | ISSN: 2381-2052

Journal Of Otolaryngology Head \& Neck Surgery | ISSN: 2573-010X

Journal Of Pathology Clinical \& Medical Research

Journal Of Pharmacology Pharmaceutics \& Pharmacovigilance | ISSN: 2639-5649

Journal Of Physical Medicine Rehabilitation \& Disabilities | ISSN: 2381-8670

Journal Of Plant Science Current Research | ISSN: 2639-3743

Journal Of Practical \& Professional Nursing | ISSN: 2639-5681

Journal Of Protein Research \& Bioinformatics

Journal Of Psychiatry Depression \& Anxiety | ISSN: 2573-0150

Journal Of Pulmonary Medicine \& Respiratory Research | ISSN: 2573-0177

Journal Of Reproductive Medicine Gynaecology \& Obstetrics | ISSN: 2574-2574

Journal Of Stem Cells Research Development \& Therapy | ISSN: 2381-2060

Journal Of Surgery Current Trends \& Innovations | ISSN: 2578-7284

Journal Of Toxicology Current Research | ISSN: 2639-3735

Journal Of Translational Science And Research

Journal Of Vaccines Research \& Vaccination | ISSN: 2573-0193

Journal Of Virology \& Antivirals

Sports Medicine And Injury Care Journal | ISSN: 2689-8829

Trends In Anatomy \& Physiology | ISSN: 2640-7752

Submit Your Manuscript: https://www.heraldopenaccess.us/submit-manuscript 